\title{
Improving access to palliative care for persons with Parkinson disease
}

\author{
Usha Ramanathan $^{1,2}$, Peter Tanuseputro ${ }^{3,4,5}$ \\ ${ }^{1}$ Faculty of Medicine, University of Toronto, Toronto, Canada; ${ }^{2}$ Division of Neurology, Scarborough Health Network, Toronto, Canada; \\ ${ }^{3}$ Department of Medicine, Ottawa Hospital Research Institute, University of Ottawa, Ottawa, Canada; ${ }^{4}$ Bruyère Research Institute, Ottawa, Canada; \\ ${ }^{5}$ ICES - Population Health and Primary Care, Ottawa, Ontario, Canada \\ Correspondence to: Usha Ramanathan, MD, MSc, FRCPC. Division of Neurology, Scarborough Health Network, Scarborough General Hospital. \\ Suite 206 - 3030 Lawrence Avenue East, Scarborough, Ontario M1P 2T7, Canada. Email: uramanat@ualberta.ca. \\ Provenance and Peer Review: This article was commissioned by the Editorial Office, Annals of Palliative Medicine. The article did not undergo external \\ peer review. \\ Comment on: Fleisher JE, Klostermann EC, Hess SP, et al. Interdisciplinary palliative care for people with advanced Parkinson's disease: a view from \\ the home. Ann Palliat Med 2020;9:S80-9.
}

Submitted Oct 31, 2019. Accepted for publication Nov 30, 2019.

doi: 10.21037/apm.2019.11.10

View this article at: http://dx.doi.org/10.21037/apm.2019.11.10

Growing literature suggests that persons with Parkinson disease have increased palliative care needs. Specifically, nonmotor symptoms (such as pain) are often underrecognized and undertreated, there is inadequate psychosocial support, there are increased rates of nursing home placement and hospitalization especially in the last year of life, and caregivers face increased burden of responsibility (1). There is established evidence that palliative care improves quality of life for persons with Parkinson disease (2). There are consensus statements supporting the early integration of palliative care into neurological care for persons with Parkinson disease, with involvement of multidisciplinary teams, as well as involvement of patients and caregivers in advance care planning (3).

However, it is also known that current provision of palliative care to persons with Parkinson disease is limited. In developed countries, palliative care is being delivered primarily to younger patients, with less multimorbidity, who live in urban or socially affluent neighbourhoods, and with cancer diagnoses $(4,5)$.

In this issue of "Annals of Palliative Medicine", Fleisher and colleagues (6) attempt to address this gap in palliative care provision for persons with Parkinson disease by developing a new model of care delivery. They trialed two models of interdisciplinary home visits for homebound persons with Parkinson disease. Both models involved nurse, social worker, and movement disorder specialist.
The movement disorder physician performed home visits in the first model, and telemedicine visits in the second. The purpose of these home visits was to address motor and non-motor symptoms, perform medication reconciliation, identify home safety concerns as well as address psychosocial concerns. The rationale for telemedicine visits was to improve cost-effectiveness and efficiency. Study outcomes included: patient quality of life, advance directives completion, discovery of medication errors, and home safety evaluations.

The study results reflect a number of known issues that affect persons with Parkinson disease, such as: prevalence of orthostatic hypotension requiring drug regimen modification, multimorbidity (often patients have comorbid diagnosis of dementia or mobility issues), polypharmacy, as well as social isolation.

Fleisher and colleagues' unique model of care has multiple advantages. First, involvement of a movement disorder specialist results in nuanced care specific to Parkinson disease, such as evaluation of the efficacy of the mediation regimen and medication adjustments to manage reversible symptoms (such as orthostatic hypotension), and allows the medical care to focus on patient-centred outcomes and quality of life.

Emerging evidence suggests that palliative care needs of the general population will increase significantly (7), due to older age and comorbid conditions such as dementia. 
It will be difficult, however, for all patients to receive specialist palliative care. One population level study, in a health system with universal healthcare coverage, found that only about 1 in 4 persons will have any contact with a palliative care specialist physician in the last year of life (8). Therefore, the onus is on neurologists to improve their skills in order to provide fundamental palliative care to their patient population. This can be partially done via improved educational resources for physicians and trainees who are not palliative care specialists (9).

Second, the use of telemedicine to conduct home visits increases efficiency of palliative care services, reducing travel time required to visit home-bound patients. Telemedicine can offer more regular assessments so that changes in performance status can be captured sooner and so that resources can be deployed to those with high needs. Telemedicine also allows neurological and palliative care to reach patients living in different settings, including longterm care facilities. As such there is increasing interest in provision of telehealth palliative care (10).

Aging in place is a concept that should be embraced. While most patients prefer to receive care and die at home, some patients alter their preference as the illness progresses (11). Home can be the ideal place of care if the patient and caregiver have access to necessary resources. As such, without adequate assistance available in the home, we should be wary of placing undue emphasis on home as the ultimate place of care. Alternate venues such as hospices and assisted living homes should also receive support and funding from policy-makers.

The study model proposed by Fleisher and colleagues can be considered a gold standard of care with respect to involvement of the movement disorder specialist, nurse, social worker, and multidisciplinary team. Similar palliative care services have been offered in Italy, for persons with neurodegenerative disorders, via the NE-PAL project (12) and in the UK via an outpatient short-term palliative care service for persons with Multiple Sclerosis (13). However, the question remains: how feasible is it to scale up these models to the entire neurological patient population, with respect to costs as well as technological and human resources?

One possibility is to replicate the study model in other locations using already available community resources. A movement disorder physician, for example, could work with home care nurses and personal support workers to coordinate different aspects of the care. Another possibility is for a shared care model, involving both neurologists and primary care physicians, with the movement disorders specialist providing consultative opinion while the primary care team provides the multidisciplinary support for patients and their caregivers. Telehealth services could also be implemented into nursing homes that may already have the infrastructure for such services, so that residents can also benefit from specialized neurology-palliative care input. A novel way of addressing social isolation faced by patients with chronic illnesses is the use of communitybased volunteers and services. This includes taking a public health approach to end-of-life care, where 'palliative care is everyone's business'. Irrespective of mode of delivery, palliative care services need to be scaled up, since it has been shown that only a minority of the population receives specialized services.

Another question that is raised by Fleisher and colleagues' study is how to evaluate the effectiveness of these home visit interventions. Neurology-palliative care interventions are complex interventions, by virtue of the number of care providers involved, the number of symptoms being managed and the long-term nature of the illness. Evaluation of effectiveness of interventions requires use of validated outcome measures (such as ESAS-PD) as well as use of mixed methods approaches (both qualitative and quantitative data collection). There is also paucity of cost effectiveness data about palliative care interventions, limiting uptake by policy-makers.

It is an exciting time in the field of neurology-palliative care with a significant opportunity to improve care. More research should be directed towards addressing the palliative care needs of persons with Parkinson disease. The emphasis should be on patient-centred outcomes and goals of care. Future research should focus on how to increase appropriate, high quality, community-based palliative care for greater numbers of patients and caregivers.

\section{Acknowledgments}

Funding: None.

\section{Footnote}

Conflicts of Interest: The authors have no conflicts of interest to declare.

Ethical Statement: The authors are accountable for all aspects of the work in ensuring that questions related to the accuracy or integrity of any part of the work are 
appropriately investigated and resolved.

Open Access Statement: This is an Open Access article distributed in accordance with the Creative Commons Attribution-NonCommercial-NoDerivs 4.0 International License (CC BY-NC-ND 4.0), which permits the noncommercial replication and distribution of the article with the strict proviso that no changes or edits are made and the original work is properly cited (including links to both the formal publication through the relevant DOI and the license). See: https://creativecommons.org/licenses/by-nc-nd/4.0/.

\section{References}

1. Kluger BM, Fox S, Timmons S, et al. Palliative care and Parkinson's disease: Meeting summary and recommendations for clinical research. Parkinsonism Relat Disord 2017;37:19-26.

2. Kluger BM, Katz M, Galifianakis N, et al. Does outpatient palliative care improve patient-centered outcomes in Parkinson's disease: Rationale, design, and implementation of a pragmatic comparative effectiveness trial. Contemp Clin Trials 2019;79:28-36.

3. Oliver DJ, Borasio GD, Caraceni A, et al. A consensus review on the development of palliative care for patients with chronic and progressive neurological disease. Eur J Neurol 2016;23:30-8.

4. Tanuseputro P, Budhwani S, Bai YQ, et al. Palliative care delivery across health sectors: A population-level observational study. Palliat Med 2017;31:247-57.

5. Allsop MJ, Ziegler LE, Mulvey MR, et al. Duration and determinants of hospice-based specialist palliative

Cite this article as: Ramanathan $\mathrm{U}$, Tanuseputro P. Improving access to palliative care for persons with Parkinson disease. Ann Palliat Med 2020;9(2):149-151. doi: 10.21037/apm.2019.11.10 care: A national retrospective cohort study. Palliat Med 2018;32:1322-33.

6. Fleisher JE, Klostermann EC, Hess SP, et al. Interdisciplinary palliative care for people with advanced Parkinson's disease: a view from the home. Ann Palliat Med 2020;9:S80-9.

7. Etkind SN, Bone AE, Gomes B, et al. How many people will need palliative care in 2040? Past trends, future projections and implications for services. BMC Med 2017;15:102.

8. Brown CR, Hsu AT, Kendall C, et al. How are physicians delivering palliative care? A population-based retrospective cohort study describing the mix of generalist and specialist palliative care models in the last year of life. Palliat Med 2018;32:1334-43

9. Creutzfeldt CJ, Kluger B, Kelly AG, et al. Neuropalliative care: Priorities to move the field forward. Neurology 2018;91:217-26.

10. Tieman JJ, Swetenham K, Morgan DD, et al. Using telehealth to support end of life care in the community: a feasibility study. BMC Palliat Care 2016;15:94.

11. Gomes B, Calanzani N, Gysels M, et al. Heterogeneity and changes in preferences for dying at home: a systematic review. BMC Palliat Care 2013;12:7.

12. Veronese S, Gallo G, Valle A, et al. Specialist palliative care improves the quality of life in advanced neurodegenerative disorders: NE-PAL, a pilot randomised controlled study. BMJ Support Palliat Care 2017;7:164-72.

13. Higginson IJ, McCrone P, Hart SR, et al. Is shortterm palliative care cost-effective in multiple sclerosis? A randomized phase II trial. J Pain Symptom Manage 2009;38:816-26. 